\title{
Abstract
}

\section{Single domain human immunoglobulin fold-based biomolecules}

Simon E. Hufton

Target Quest B.V. ${ }^{1}$, University Hospital Maastricht, PO Box 5800, 6202 AZ Maastricht, The Netherlands

We have developed human immunoglobulin fold containing proteins as alternative binding ligands to antibodies. Firstly, we have evaluated cytotoxic T lymphocyte associated antigen 4 (CTLA-4) as a protein scaffold. CTLA-4 is an important regulator of cellular immunity and is transiently expressed on the surface of $\mathrm{T}$ cells. To have a suitable library selection system we have displayed the extracellular domain of CTLA-4 in a functional form on the surface of filamentous phage. We have generated both engineered CTLA-4 variants and repertoires of CTLA-4 variants from which binding ligands to somatostatin receptors and $\alpha \mathrm{v} \beta 3$ integrin have been isolated.

We have also investigated the potential of single VL domains as binding ligands From a naïve repertoire, single VL domains were isolated which were able to bind to B7-1 and B7-2 which are important costimulatory molecules on antigen presenting cells.

We believe that these monomeric immunoglobulins may present certain advantages over classical antibodies for certain applications.

${ }^{1}$ A subsidiary of Dyax Corp. 


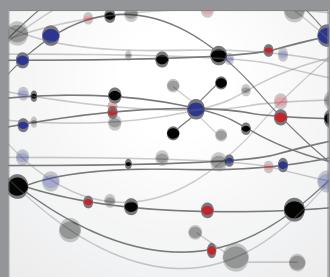

The Scientific World Journal
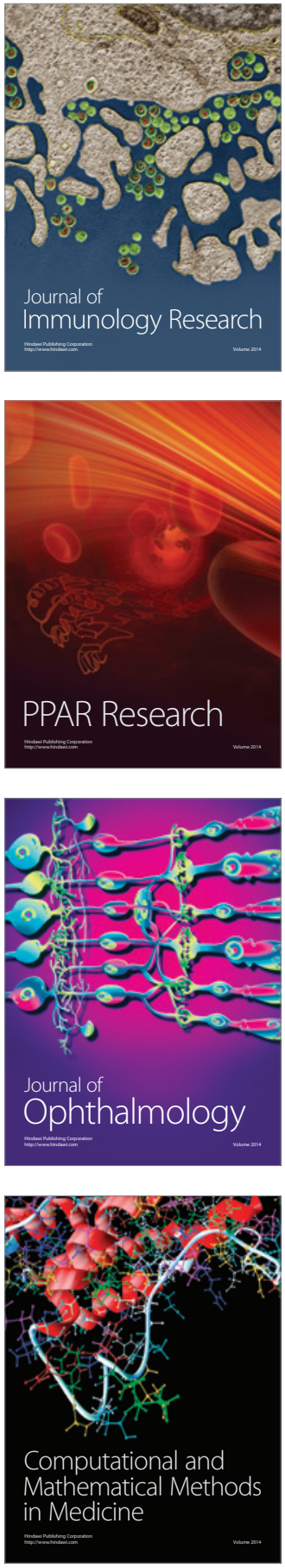

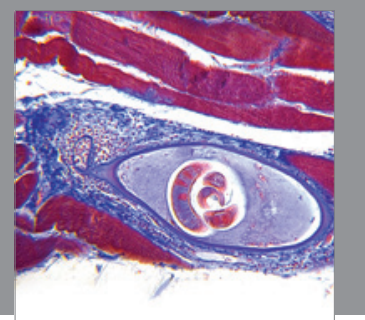

Gastroenterology

Research and Practice
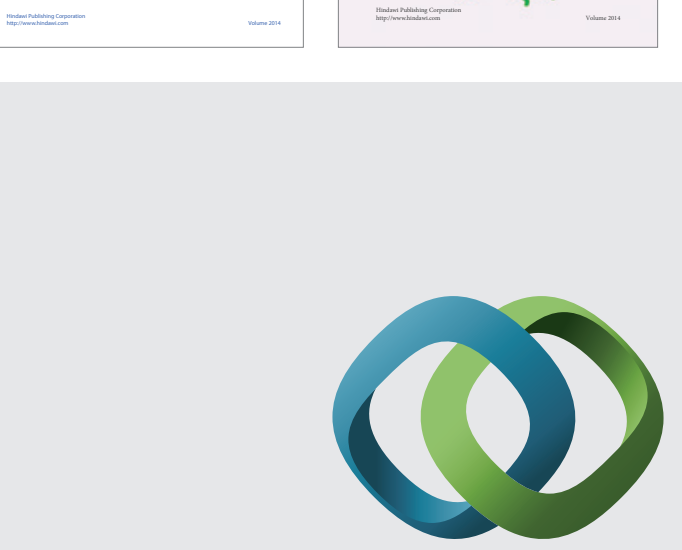

\section{Hindawi}

Submit your manuscripts at

http://www.hindawi.com
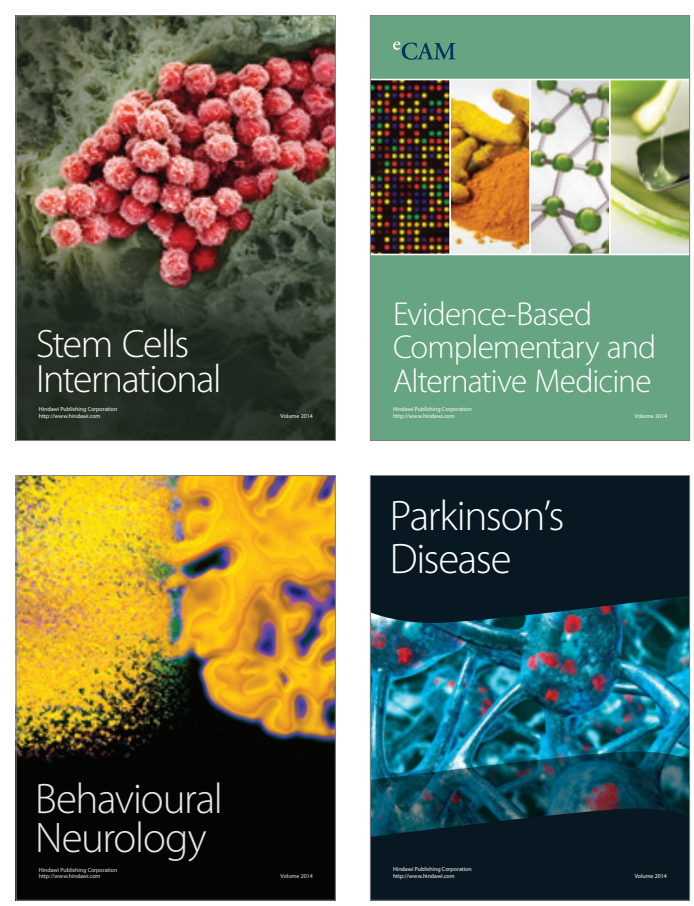

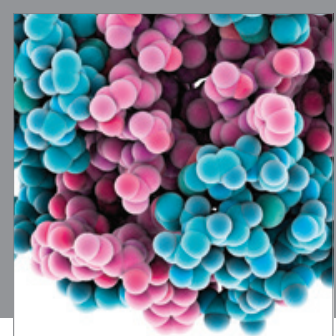

Journal of
Diabetes Research

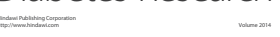

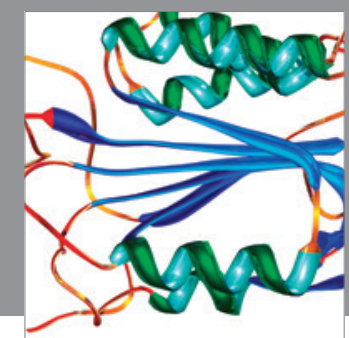

Disease Markers
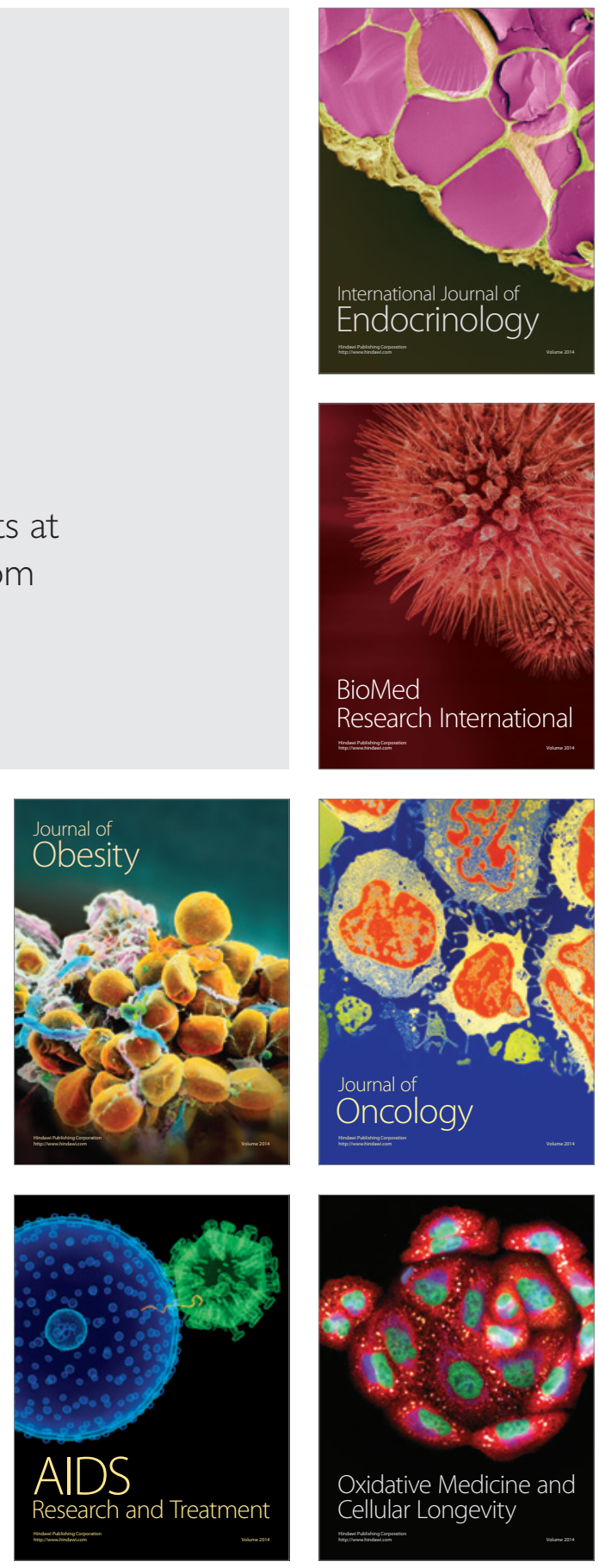